\title{
Trabalho e deficiência: as cooperativas como estratégia de inclusão social
}

\author{
Work and disability: cooperativism \\ and social inclusion
}

Maria Isabel Garcez Ghirardi ${ }^{1}$

\begin{abstract}
GHIRARDI, M. I. G. Trabalho e deficiência: as cooperativas como estratégia de inclusão social. Rev. Ter. Ocup. Univ. São Paulo, v. 15, n. 2, p. 49-54, maio/ago., 2004.

RESUMO: $O$ artigo pretende discutir as cooperativas de trabalho como espaços de inclusão social de pessoas com deficiência, a partir do relato de uma intervenção que resultou na constituição de uma cooperativa de trabalho mista. Parte-se da concepção da economia solidaria e do cooperativismo como contraponto ao modo de produção capitalista, a fim de refletir a respeito da construção de espaços solidários em que pessoas afastadas do trabalho e que tenham ou não algum tipo de deficiência possam estabelecer uma base de trocas materiais e afetivas.
\end{abstract}

DESCRITORES: Pessoas portadoras de deficiência/reabilitação. Trabalho. Estratégias. Ajustamento social. Comportamento cooperativo.

Trabalho e deficiência na perspectiva da economia solidária

$$
\text { A }
$$
deficiência pode trazer algumas limitações que vão se refletir na vida quotidiana do sujeito, nas ações e nas relações que dia a dia nos asseguram um espaço de existência social. As limitações que podem decorrer da deficiência são eventualmente traduzidas no ambiente da vida quotidiana como incapacidades, impedimentos de origem individual e como tal têm sido históricamente abordados. Dessa maneira, a eventual superação de uma limitação, seria uma questão que se coloca sempre para o outro, que deve buscar o meio possível para se capacitar a participar do ambiente social quotidiano. Blanc (1999) nos lembra que "a pessoa com deficiência em geral, o trabalhador com deficiência em particular, são sujeitos da falta" (p.17).

Recentemente, um movimento vem sendo feito no sentido de resgatar elementos que permitam reconsiderar a complexidade implicada no processo de segregação e exclusão social da alteridade. As intervenções sociais que se propõem a enfrentar o desafio de produzir espaços sociais em que a diversidade seja

\footnotetext{
${ }^{1}$ Docente do curso de Terapia Ocupacional - FMUSP. Doutora em Psicologia Social e do Trabalho.

Endereço para correspondência: Departamento de Fisioterapia, Fonoaudiologia e Terapia Ocupacional da Faculdade de Medicina da Universidade de São Paulo. Rua Cipotânea, 51. Cidade Universitária - CEP: 05360-000 - São Paulo, SP.
} 
possível, permitem a emergência de conflitos que estão muito além da fronteira individual da diferença (STIKER, 1999).

Focalizando os espaços vitais das pessoas com deficiência ou em processos de desafiliação, privilegiando a rede de trocas e de relações humanas que acontece no quotidiano, novas propostas de intervenção social têm buscado privilegiar, não mais a clínica e o espaço terapêutico individual, mas trazem o foco da discussão para o espaço do quotidiano e seu contexto, ao mesmo tempo coletivo e cambiante. Nessa perspectiva, o lazer, o trabalho, a moradia e a educação, os cenários do quotidiano, permitem delinear movimentos e percursos que revelam a complexidade da inserção social de sujeitos diversos.

É, portanto, na perspectiva de criar espaços quotidianos que engendrem a possibilidade de transformações de relações sociais cristalizadas e que impliquem diversos sujeitos sociais, que temos aceitado o desafio construir relações que visem à “(...) criação e a multiplicação de oportunidades de trocas materiais e afetivas como a tessitura de uma "rede de negociações"; as redes de negociação, na medida em que são articuladas e flexíveis, aumentam a participação e a contratualidade reais dos sujeitos sociais frágeis; poder-se-ia dizer que o mercado (ou seja o local físico e social das trocas de mercadorias) precede e determina em uma comunidade a possibilidade de relações entre seus membros" (SARACENO, 1995, p.79-80) .

A participação no mercado de trocas, de produção e de consumo de bens coletivos pode ser, então, um ponto de partida para a inclusão social de diversas alteridades. Ao se considerar o trabalho como ponto de partida de um processo que pretende viabilizar um resgate de subjetividades, supõe-se que é no trabalho, como base concreta de comunicação, que se estabelecem redes de negociação e de trocas, que possibilitam que as relações com a alteridade adquiram maior complexidade.

Estar incluído em nossa sociedade pode, então, ser também traduzido pelo potencial de produção e consumo que cada sujeito demonstra. Ser um sujeito social, significa também estar em condição de participar da rede de produção/consumo da coletividade. É a possibilidade de produzir valores de troca reconhecidos socialmente; é ter condições para ampliar ou ter garantido o seu poder de realizar contratos sociais.

Blanc (1999) sugere que a desqualificação social a que as pessoas com deficiência estão submetidas pode ser ilustrada por quatro elementos que estão encadeados em suas vidas, a saber: escolarização precária; dispositivos de formação e reabilitação profissional inadequados às demandas de empregos disponíveis; a evolução da natureza dos empregos (qualificação prévia, disponibilidade) que impede o acesso das pessoas com deficiência ao mercado de trabalho e, finalmente, a crise atual de empregos que faz com que essas pessoas tenham que concorrer com outros excluídos sociais não deficientes. Todo esse quadro, segundo Blanc (1999) geraria uma situação de desânimo entre as pessoas com deficiência que terminariam por recolher suas vidas em zonas de não trabalho.

Em nosso país, a situação da inserção de pessoas com deficiência no trabalho ainda tem sido pouco estudada pela área econômica. Pastore (2000) ao discutir as oportunidades de trabalho para pessoas com deficiência no Brasil, chama a atenção para a falta de dados a esse respeito na área econômica e considera que em nossa realidade, apenas $2 \%$ do total de pessoas com deficiência em idade de trabalhar estejam empregadas. Ou seja, apenas 180 mil pessoas com deficiência teriam emprego com carteira assinada ou autônomos, mas com as proteções de seguridade social.

Esses dados demonstram a necessidade de desenvolvimento de pesquisas e intervenções alternativas que discutam a situação de inclusão no mercado de trabalho de pessoas com deficiência no Brasil.

Uma das alternativas possíveis para se pensar a inclusão de pessoas num mercado de trabalho cada vez mais restrito tem sido as cooperativas, que emergem dentro da concepção da economia solidária.

A economia solidária surge como modo de produção e distribuição alternativo ao capitalismo, criado e recriado periodicamente pelos que se encontram (ou temem ficar) marginalizados do mercado de trabalho (SINGER, 2000, p.13).

Assim as cooperativas se constituem como empresas e não como um dispositivo terapêutico ou clínico. Essas empresas não se constróem dentro do modo de produção capitalista, mas sim a partir da proposta da economia solidária. Pensar o cooperativismo como alternativa possível para a inclusão social pela via do trabalho é aceitar o desafio de produzir uma intervenção transdisciplinar que, a partir da apropriação do conhecimento de diversas áreas procure encontrar um lugar de existência para além do âmbito da saúde. Um espaço pautado pela lógica das trocas sociais e não pela lógica do universo da saúde e da doença.

No Brasil, apenas atualmente é que as cooperativas têm sido pensadas como possibilidade de espaço inclusivo no quotidiano da sociedade. Poucas 
experiências têm sido acompanhadas e não se conhece ainda qualquer trabalho nacional de pesquisa que reflita sobre essa experiência de inclusão social para pessoas com deficiência.

Ocupar espaços de trabalho não exclusivos constitui-se numa estratégia de intervenção social que permite enfrentar as situações de estigmatização que têm lugar nas relações sociais entre pessoas com e sem deficiência. Por outro lado, o espaço de produção e consumo de bens sociais é fundamental na constituição da identidade social do sujeito, uma vez que os sujeitos sociais “(...) manifestam através do que consomem, seu lugar no conjunto social” (CASTEL, 1995, p. 596).

\section{quotidiana}

\section{Construindo um espaço de cooperação}

A cooperativa TRAMART formou-se no início do ano 2000, com a proposta de constituir-se num espaço de trabalho inclusivo, de acordo com a perspectiva da reabilitação social, tomando o próprio trabalho como ponto de partida para a transformação de relações sociais cristalizadas. Essa cooperativa que se organizou em torno da produção de artesanatos foi composta por artesãos com diversas características e habilidades, tendo eles ou não algum tipo de deficiência.

A experiência que se desenrolou durante os dois anos em que acompanhei o processo de formação dessa cooperativa permitiu uma refelexão que pode contribuir para ampliar a participação de pessoas com deficiência no mercado de trabalho. Essa cooperativa teve como pressuposto a criação de um espaço em que o convívio entre pessoas com características bastante diversas estivesse pautado pelas relações de produção e de trocas cooperativas quotidianas.

A perspectiva de ação na TRAMART teve como foco noção de desvantagem, a partir do pressuposto de que relações sociais só podem ser modificadas no processo de construção quotidiano de trocas. Trocas que implicam a existência de vários sujeitos sociais, com ou sem deficiência, dispostos a realizar transformações e inventar novas formas de relações que não sejam pautadas apenas pelo estigma, pelo estereótipo ou pelo preconceito. O debate, aqui, deixa de ser pautado pelo prisma individual e passa a se desenrolar no plano das relações duais ou sociais. A intervenção que se propõe é, portanto social, visando a inclusão pautada por uma relação social que implica tanto a ação do sujeito em direção ao coletivo, quanto do coletivo em direção ao sujeito, uma vez que o lugar socialmente ocupado pela pessoa com deficiência decorre não só de suas eventuais limitações, mas também de uma dificuldade ou, se preferirmos de uma impermeabilidade social em relação ao diverso. Nesse sentido, é necessário que a intervenção ocorra no espaço social, de maneira a produzir, a partir da perspectiva da alteridade, uma ruptura radical com as formas estigmatizantes de relação

O processo de incubação de uma cooperativa corresponde ao tempo necessário para a criação de um espaço solidário de trocas e se estende até o momento em que a cooperativa atinge plenamente a possibilidade de auto-gestão.

Realizar o processo de incubação de uma cooperativa mista, que se propunha a ser um dispositivo econômico, muito além do espaço da saúde, foi um desafio cuja complexidade tornou-se evidente logo nos primeiros contatos com o grupo de cooperados.

A proposta inicial era de que aquele espaço se constituisse numa possibilidade de geração de renda para pessoas que, por variados motivos, encontravamse afastadas há muito tempo do mercado formal de trabalho. Por outro lado, ao aceitar pessoas com deficiência nesse grupo, era necessário que estiviessemos atentos para não cair na fácil armadilha de imputar à deficiência ou às eventuais incapacidades, as frustrações inerentes ao processo de constituição de uma cooperativa de trabalho.

Dessa forma, o trabalho de incubação de uma cooperativa mista tem características particulares, uma vez que envolve um olhar atento para as características do mercado em que a cooperativa pretende estar inserida, mas envolve, também, uma atenção específica para as relações interpessoais que ocorrem no interior do grupo de cooperados. Essas relações tendem a reproduzir aquelas que tradicionalmente se desenvolvem no contato quotidiano com pessoas com deficiência. Mesmo, e talvez sobretudo, num espaço de produção econômica, o estigma se traduz em relações cristalizadas em que a falta está sempre no outro, na incapacidade. Assim, um cuidadoso processo de incubação deve quotidianamente trazer a discussão das dificuldades e mesmo das eventuais impossibilidades, para o espaço relacional, de maneira a implicar todos os sujeitos seja na produção de bens materiais, seja na produção de uma nova perspectiva de colaboração e de trocas em que os limites e as habilidades transformem e potencializem esse espaço de produção.

Várias são as questões que permeiam a constituição desse tipo de cooperativa, gostaria de destacar aqui apenas algumas das que me parecem mais relevantes.

Uma delas diz respeito ao fato de que as pessoas com deficiência que frequentaram espaços de 
profissionalização trazem consigo para a cooperativa o resultado de algumas distorções que o processo de reabilitação institucional produz, por exemplo, em relação ao produto. Em geral, essas pessoas entendem que o simples fato de estarem se propondo a produzir algo é suficiente para que esse produto seja vendável. Acreditam, conforme propagado pelas instituições de reabilitação, que são incapazes de produzir algo possível de concorrer no mercado com produtos similares. Nesse sentido, trabalham com vistas a vender a deficiência, e não o produto.

É comum observarmos esse conceito ser difundido em alguns bazares de instituições filantrópicas, por exemplo, na época de final de ano. $\mathrm{O}$ apelo veiculado pela mídia televisiva em geral atesta essa perspectiva institucional que busca apelar para a caridade social em relação às pessoas com deficiência, sugerindo que a compra dos produtos institucionais é uma forma de contribuir para uma instituição que se coloca indispensável para a vida das pessoas com deficiência. Assim, nesses bazares, muito mais do que o produto do trabalho das pessoas com deficiência, vende-se o trabalho da instituição. Muitas vezes as pessoas com deficiência entendem que vender a deficiência é uma forma mais rápida de se ter o retorno econômico do próprio trabalho. De certa maneira isso pode até ser verdadeiro, porém a médio e a longo prazo, essa relação tenderá apenas a perpetuar o lugar marginal que essas pessoas ocupam, impedindo sua autonomia como sujeito social.

Em geral, as pessoas com deficiência que se propõem a participar de uma cooperativa vêm com essa perspectiva fortemente introjetada e resistem à idéia de que a cooperativa tenha um controle de qualidade sobre a produção, uma vez que não tem como proposta vender a deficiência, a loucura ou a exclusão social. Uma cooperativa é um dispositivo econômico e, como tal, pretende se constituir como uma empresa auto-gerida que concorre num mercado produtivo altamente especializado.

Disso decorre um outro aspecto interessante que se podeobservar numa cooperativa inclusiva, que é o fato de que a pessoa com deficiência deve progressivamente abandonar a identidade de deficiente e passar a assumir a identidade de trabalhador, com todas as controvérsias que essa identidade implica.

Deixar de ocupar o lugar social reservado à pessoa com deficiência e passar a ocupar o espaço de um sujeito produtivo e eficiente, sair do espaço de tutela e se constituir como sujeito autônomo é um caminho árduo que exige disposição de todos os cooperados.

Fica evidente, nas relações quotidianas de trabalho que o estigma deixa sua marca também nas micro-relações que têm espaço mesmo dentro da cooperativa. Às vezes para um cooperado que não apresenta qualquer problema físico ou psíquico, é desconfortável esperar, por exemplo nas assembléias gerais, que as pessoas com maior dificuldade possam compreender o âmbito da discussão e expressar sua opinião. Ora, uma cooperativa só se constitui na medida em que todos os membros participem das assembléias, com direto a opinar e a votar de forma igualitária em todos os itens da pauta, essa é uma questão se coloca para todos os cooperados e não apenas para aqueles que têm alguma deficiência.

Muitas vezes a comunicação com pessoas surdas, ou com deficiência mental, por exemplo, é dificultada tanto pela limitação das próprias pessoas, quanto pela dificuldade de outros cooperados em estabelecerem um canal de comunicação viável. Várias vezes, é mais fácil para um cooperado que enxerga, intervir no trabalho de tecelagem de uma pessoa cega, por exemplo, do que aguardar que a pessoa se dê conta de que o trabalho não está bom e busque discutir adaptações que possam facilitar seu trabalho. Nesses momentos é fundamental que o trabalho de incubação possa remeter a discussão ao coletivo dos cooperados, evitando que se recorra ao modelo estigmatizante de relação dual em que a incapacidade é um problema do outro.

De forma complementar a essa discussão uma outra se esboça: discute-se o valor do trabalho. $\mathrm{O}$ valor da mercadoria é, como se sabe, em parte subjetivo, porque não pode ser mensurada a força de trabalho empregada para se realizar cada trabalho. Pois essa discussão também tem que ser enfrentada em sua complexidade, por todos os componentes da cooperativa que ora acreditam que o trabalho está subestimado, ora super estimado. Aqui também está em confronto o individual e o social que define mercado, mercadoria e valores de troca.

É, portanto, imprescindível que o foco da incubação seja mantido no âmbito da produção coletiva, para dessa maneira superar as limitações individuais e debater as questões dentro da cooperativa que se propõe a produzir a partir e através da diversidade. Limitações, rítmos de produção, qualidade dos produtos são aspectos debatidos nas assembléias com a participação de todos os cooperados e entendidos como questões coletivas, evitando-se a polarização competitiva comum ao modo de produção capitalista.

Outras questões, essas de ordem burocrática, também intervém na organização do trabalho. Por exemplo, para ser um cooperado, a pessoa deve estar 
registrada como trabalhador autônomo. Porém, registrarse como autônomo significa abrir mão da aposentadoria por invalidez ou da pensão que muitas pessoas com deficiência recebem e que se constitui, até então, na única fonte segura de renda para essas pessoas

Assim, o trabalho de constituir uma cooperativa inclusiva é um desafio de proporções consideráveis, e que só pode ser enfrentado coletivamente.

A complexidade inerente a esse tipo de intervenção pode ilustrada também pelo relato de alguns aspectos que envolvem o de comercialização da produção dos cooperados. Esse processo pretende possibilitar um espaço que constitua como criador e multiplicador $d e$ oportunidades de trocas materiais e afetivas, uma vez que está imerso diretamente no cenário do mercado social quotidiano e que pode contribuir para a transformação das relações e da ampliação da capacidade contratualidade social das pessoas com deficiência.

Participar das diversas feiras de artesanato que têm lugar ao longo do ano na cidade de São Paulo coloca à prova a própria organização da cooperativa. É um tipo de experiência que se pode qualificar como radical. Radical porque expõe produtos e produtores à apreciação pública, num espaço de consumo bastante exigente. Todos os cooperados participam das vendas, rodiziando-se em grupos durante o dia em que acontece a feira. É interessante observar a relação que se desenvolve entre os exigentes consumidores da feira e os cooperados. Em alguns momentos talvez se perca a oportunidade de fazer uma boa venda, por inexperiência do vendedor ou por incapacidade de comunicação entre consumidor e produtor. Porém as vendas acontecem. E vende-se os produtos e não a deficiência.

Essa experiência também nos mostra a dificuldade do público em compreender o que se passa ali. Por alguns momentos podemos observar as pessoas num estado que em psicologia chamamos de dissonância cognitiva. Ou seja as pessoas não conseguem admitir que belos trabalhos sejam feitos por pessoas que tenham limitações aparentes. Tendem a se dirigir àquelas pessoas que são aparentemente normais. Mas aos poucos têm percebido que aquela produção coletiva é fruto da diversidade que a cooperativa busca contemplar, e todos ali produzem e vendem os trabalhos expostos. Aos poucos o público vai sendo exposto a essa situação em que pessoas com deficiências aparentes vendem não suas deficiências, comercializam não a boa vontade, mas vendem a preço justo mercadorias de qualidade.

É interessante observar que, a partir dessa experiência de comércio, as pessoas começam a se transformar e a pensar em soluções próprias para superar suas possíveis limitações, de forma a melhorar não só a qualidade de produção, mas também de venda dos produtos de seu trabalho. Para os cooperados, de uma forma geral, essa experiência os coloca numa situação até então inusitada, em que eles ocupam um papel social central, e não mais marginal, transformando a relação que esses podem estabelecer consigo e com os outros.

A cooperativa TRAMART estruturou-se como uma pequena empresa, produzindo artesanato de qualidade, mas também produzindo uma intervenção social de alta complexidade, de impacto e de transformação de relações sociais.

A experiência de incubação da TRAMART, embora circunscrita em um determinado período, permitiu que se fortalecesse a certeza de que é na trama das relações quotidianas que a possibilidade da alteridade se encontra.

GHIRARDI, M. I. G. Work and disability: cooperativism and social inclusion. Rev. Ter. Ocup. Univ. São Paulo, v. 15, n. 2, p. 49-54, maio/ago., 2004.

\begin{abstract}
Having as a departing point an intervention which resulted in the creation of a mixed work cooperative, this paper aims at discussing work cooperatives as a space for the social inclusion of handicapped people. The notions of economic solidarity and cooperativism are used as an alternative to the capitalist logic of production so as to bring up a reflection on the establishing of spaces of solidarity in which people who are out of work - be them handicapped or not - may establish a basis for both material and emotional exchange.
\end{abstract}

DESCRITORES: Disabled persons/rehabilitation. Work. Strategies social adjustment. Cooperative behavior. 
GHIRARDI, M. I. G. Trabalho e deficiência. Rev. Ter. Ocup. Univ. São Paulo, v. 14, n. 2, p. 49-54, maio/ago., 2004.

\section{REFERÊNCIAS}

BLANC, A. Les aléas de la discrimination positive. Esprit, v.12, n. 259, p. 17-32, 1999.

CASTEL, R. Les métamorphoses de la question sociale. Paris: Gallimard, 1995.

PASTORE, J. Oportunidades de trabalho para portadores de deficiência. São Paulo: LTr, 2000.

Recebido para publicação: 30/04/04

Aceito para publicação: 20/06/04
SARACENO, B. La fine dell'intrattenimento. Manuale di riabilitazione psichiatrica. Milão: ETASLIBRI, 1995.

SINGER, P. A economia solidária no Brasil. A auto gestão como resposta ao desemprego. São Paulo: Contexto, 2000.

STIKER, H. J. Quand les personnes handicapées bousculent les politiques sociales. Esprit (Paris), v. 12, n. 259, p. 75106, 1999. 